\title{
USING NORMATIVE THEORY TO EXPLAIN THE EFFECT OF RELIGION AND EDUCATION ON VOLUNTEERING
}

\author{
JOONMO SON \\ National University of Singapore \\ JOHN WILSON \\ Duke University
}

\begin{abstract}
Many studies have found that volunteers tend to be more religious and better educated, but it is not clear why. One explanation is that churches and schools instill a sense of obligation in people to help others and this obligation is fulfilled by doing volunteer work. In this study data from National Survey of Midlife in the United States are used to examine the influence of education and having been raised in a religious home on adults' sense of obligation and subsequent volunteering. Religious background has no direct effect on sense of obligation. However, it exerts an influence on obligation through private (but not public) adult religiosity. Education has both direct and indirect effects (through obligations) on adult volunteering. The results underline the fact that social norms should not be ignored in explanations of volunteerism.

Keywords: volunteering, obligations, education, religion
\end{abstract}

Volunteer work is unpaid labor intended to benefit another person, organization, or cause. In any given year just over a quarter of all Americans aged sixteen or more, nearly 61 million people, engage in some kind of volunteer work (U.S. Bureau of Labor Statistics 2008). Without volunteers many nonprofit organizations would cease to function and many government agencies would need to curtail their activities. In recent years the federal government in the United States has begun to encourage Americans to volunteer to help cut government spending and tackle social problems more effectively. The drive to recruit more volunteers has sparked new interest in finding out why people get involved in volunteer work.

Social scientists have become adept at predicting who is most likely to volunteer (Musick and Wilson 2008). The most consistent finding is that volunteers are more highly educated and more religious. No other individual characteristics are

Address correspondence to: John Wilson, Box 90088, Durham, NC 27708-0088; e-mail: jwils@soc.duke.edu.

Sociological Perspectives, Vol. 55, Issue 3, pp. 473-499, ISSN 0731-1214, electronic ISSN 1533-8673.

(c) 2012 by Pacific Sociological Association. All rights reserved. Please direct all requests for permission to photocopy or reproduce article content through the University of California Press's Rights and Permissions website, at http://www.ucpressjournals.com/reprintinfo.asp. DOI: 10.1525/sop.2012.55.3.473. 
so reliably linked to volunteerism. So robust is this relationship that, from a scientific standpoint, it would seem little is to be gained from continuing to study it: each new survey simply repeats what is already known. And yet these findings are only empirical regularities: we have much to learn about why education and religion are related to volunteerism. In what follows we will describe the research on religion, education, and volunteering and propose a normative theory to help explain the association. Normative theories are based on the idea that people's behavior can be explained by reference to social norms. These are rules of conduct that people learn early in life or infer from the current behavior of others indicating the appropriate way to behave in specific situations. Conformity brings social approbation; deviance is met with disapproval and, perhaps, sanctions.

\section{Religion, Education, and Volunteering}

Just over half (53.0 percent) of Americans who attend church every or nearly every week have engaged in volunteer work in the past twelve months, compared to 19 percent of non-churchgoers (Musick and Wilson 2008:279). Much of the volunteer work performed by frequent churchgoers revolves around the social life of the congregation itself: like any other voluntary organization, religious congregations require maintenance. But the influence of religiosity on volunteering reaches beyond the congregation. Religious people are more likely to volunteer even for secular causes. Indeed, the association between religion and volunteering is so strong in the United States that helping the needy is seen as a religious virtue, as if secularists did not share this value (Ammerman 1997:366).

For its part, education is "the most consistent, and often strongest, predictor of volunteering" (Musick and Wilson 2008:119). Among adults aged 25 or more in the United States, only 9 percent of those with less than a high school diploma volunteered in 2007 compared to 41.8 percent of those with a bachelor's degree or higher (U.S. Bureau of Labor Statistics 2008). Education also has a positive effect on various forms of "civic engagement," such as unpaid political campaign work, that are also examples of volunteer work (Brown and Ferris 2007:91; Hillygus 2005:25; Wilson 2005:13).

\section{Connecting Religion and Education to Volunteering}

When it comes to explaining why people volunteer, "resource theory" emphasizes the role of enabling resources, such as civic skills, free time, good health, and social connections (Wilson and Musick 1997). This theory assumes that volunteering is a type of labor much like any other productive activity except that it is unpaid. Like all forms of labor it consumes resources. Those who are well-endowed with these resources are most likely to volunteer. But volunteering is not just any productive activity that is unpaid; it is work intended to be of utility to others. For example, chopping wood with which to heat a house might be paid labor in some instances; it can also be unpaid labor if the wood is intended for one's own fireplace; but it is volunteer work if it is unpaid and intended for use by another person, who might be unknown to the chopper. For this reason, the resource theory fails to identify the 
sufficient conditions for volunteering, although it might correctly identify necessary conditions. Additional elements are needed to account for the altruistic behavior of volunteers. A different perspective on volunteering is provided by socialization theory, which assumes that people volunteer because they believe it is the right thing to do, a lesson they learn through their immersion in institutions such as the family, the church, and the school (Wuthnow 1995). In the next section we will outline this theory and describe how it can be applied to volunteering.

\section{A Normative Theory of Volunteering}

Human behavior is teleologically oriented to the attainment of goals and shaped by conformity with regulatory rules or norms governing how goals should be achieved. A comprehensive theory of volunteering recognizes that choosing to do unpaid labor for the benefit of others is motivated by values and guided by rules that specify the correct way to actualize those values. People volunteer not only because they can, or because they have wider social networks, or because they have an "interest" in the output of the unpaid labor, as when homeowners volunteer because they are interested in their neighborhood's reputation for safety, but also because they think it is the right thing to do. Volunteer work is not simply "a disguised form of selfishness" (Durkheim 1961:223) to be explained solely by its rewards and costs. Even the most interest-driven forms of volunteering, such as offering to work on behalf of a political campaign or social movement from which one expects to benefit, have a normative component (Campbell 2006:13). From a rational choice point of view, norms help solve the free rider problem: why should anyone, regardless of their capabilities or even their interests, volunteer to provide services to a group or community while others sit back and enjoy those services? The normative answer to this question is that people volunteer because they believe it is their duty to do so and because they expect others to do likewise. They fear the sanctions applied if they do not follow the rule and value the social approval that comes if they do follow it. And if they have internalized the norm, they feel guilty if they do not conform to it and "feel good" if they do respect it.

People frequently refer to the expectations of others when explaining why they volunteer, as in the following quotation: "The hospital was my first [volunteer experience] ... it was my teacher. It was grade six, I think it was, and ... we'd talk and stuff and there was a group of my friends and she [the teacher] said you know, this would be great for you guys to do this, so then ... I went and applied and got in and started volunteering there" (Pancer and Pratt 1999:48). When asked why they are active in civic affairs, most Americans say it is their duty to be so (Verba, Schlozman, and Brady 1995). People also refer to their "civic duty" when explaining why they volunteer (Hodgkinson and Weitzman 1996:243). Such sentiments explain why people occasionally find themselves volunteering to help people they find personally distasteful: they get satisfaction from doing the right thing and earning the approval of other members of their community (Eckstein 2001). And if norms are internalized, people value the prescribed behavior for its own sake, as when the residents of the Boston neighborhood studied by Eckstein (2001:841) explained that they volunteered because "we believe in community helping." 
To some, normative explanations look suspiciously tautological. It is not quite saying that people volunteer because they volunteer but it is close: they volunteer because they want to volunteer. This is why the argument that a person volunteers because she or he feels "an obligation to help those in the community, nation or society at large who are in need" seems platitudinous (Pancer and Pratt 1999:38). But this criticism is easily answered by many studies — and everyday experienceshowing that a verbal commitment to a norm does not predict future conformity to the norm very reliably, especially when there is a "desirability bias" attached to the norm. Influenced by this bias, people might profess their moral duty to help others without actually doing so or, if they are volunteering, give a socially approved reason for doing so rather than the real reason, such as career building or social ingratiation. Just as important, it is easy for respondents to acknowledge with all sincerity the existence of a norm without meaning to imply that the norm applies to them personally. For example, the National Survey on Philanthropy and Civic Renewal asked respondents, "How important do you feel it is for community life for people to volunteer money and time to charitable organizations?" Six in ten thought it was "very important." The survey then asked respondents if they felt that they, personally, should do volunteer work: more than half said that volunteer work was not an obligation but "entirely a matter of personal preference" (Ferree et al. 1998). This is not an isolated sociological phenomenon. The same pattern is found in norms governing relationships between races in the United States. For example, Americans can, at the same time as they express approval of interracial dating in general, decline to engage in the practice themselves (Herman and Campbell 2011). In short, invoking a theory of norms does not commit one to the viewpoint that norms are "primary, hard, and immutable" and "impervious to human agency" (Sewell 1992:2). Rather, norms are rules for social living, principles of action, whose influence over behavior is contingent on many others factors, such as personality, social and economic circumstance, and the attitudes and behaviors of others.

Skepticism about the influence of norms on volunteering is not new. More than thirty years ago Schwartz (1973:349) declared that "normative explanations of helping behavior are in disrepute nowadays." Their advocates were regarded as naïve in assuming that people would act according to principles of right and wrong rather than in their self-interest. Normative theories such as structuralfunctionalism were dismissed as encouraging an "over-socialized" image of social actors, seeming to imply that people blindly and automatically followed unchanging and unequivocal social rules (Sewell 1992). As functionalism began to lose popularity in sociology, explicit reference to social norms virtually disappeared from discussions of volunteerism. However, social scientists have lately begun to pay renewed attention to them. For example, rational choice theorists, faced with the problem of explaining phenomena such as cooperation and collective action when a basic assumption of their theory is that individuals place their own interests first, now argue that norms are one way to build the trust and solidarity needed to bring about collective action (Hechter and Opp 2001:xii). Communitarians have also helped refocus attention on the role of norms in promoting collaborative behavior. Putnam (2000) includes norms in his social capital concept. 
Together with social networks and generalized trust, social norms provide a platform to enable members of groups to act in concern to produce public goods. In the same vein, Campbell (2006) argues that civic engagement (ranging from voting to volunteering) is driven not only by interests but also by a sense of obligation or duty; that feelings of obligation are acquired through a process of socialization that starts in adolescence; and that obligations work alongside interests and resources to motivate civic engagement.

Unfortunately, studies of civic engagement or volunteerism that rely on normative explanations rarely include actual measures of norms. Campbell's study of multiple forms of civic engagement does not include specific measures of social norms; they are merely invoked as a possible explanation. Likewise, Brown and Ferris (2007:89), in examining the impact of social capital on charitable giving and volunteering, lack a direct measure of norms; instead, "norms are captured by the indices of social trust and interracial trust that relate to expectations of generalized reciprocity and the value of good citizenship reflected in the attitudes and behaviors that are measured in the electoral participation index," thus conflating two of the three components of social capital. And a brief discussion of norms in Musick and Wilson's (2008:97-103) profile of the volunteer does not move beyond documenting that volunteers are more likely than nonvolunteers to invoke norms such as reciprocity, social justice, and social responsibility to explain why they volunteer.

This failure to pursue a normativist explanation of volunteerism is regrettable because there is tantalizing evidence that norms play a positive role in getting people involved in the community, not only from studies of civic engagement but also from surveys showing that people who feel obliged to do volunteer work are indeed more likely to do it. A 1988 U.S. survey asked respondents how seriously they took their responsibility to volunteer: those who said they took it very seriously were more likely to have volunteered in the past twelve months (Sundeen 1992). Other surveys show that Americans who believe it is important to get involved in their community are more likely to volunteer, although the belief is stronger among secular than religious volunteers (Uslaner 2002:247). In 2002 and 2004 the General Social Survey asked respondents how often they had volunteered in the past year. The survey also asked respondents whether people should be willing to help others who are less fortunate than themselves, with answers coded using a 5 -point Likert-type scale $(1=$ strongly agree to $5=$ strongly disagree). We analyzed these data and found that 89.1 percent and 90.4 percent of the respondents in 2002 and 2004, respectively, either agreed or strongly agreed that people should help others who are less fortunate. In 200216.9 percent and in 200419.8 percent of those who agreed or strongly agreed with this norm volunteered at least once a month compared to 8.3 percent and 4.4 percent of those who disagreed or strongly disagreed in 2002 and 2004, respectively. The measure of agreement about the norm and the likelihood of volunteering were correlated $(0.16, p<.001)$ in both survey years. In a Canadian survey, volunteers were more likely than nonvolunteers to believe that "individuals have a responsibility to support and contribute to the common good" (Reed and Selbee 2003:97). Respondents in a 1996-1997 survey conducted in the Netherlands were asked if they believed that everybody should 
do volunteer work at times. Volunteers were more likely to agree with this statement than nonvolunteers (Dekker 2004).

The results of these studies and our own analysis of the GSS data are highly suggestive, but their design limits their usefulness for testing normative theory. First, they are cross-sectional. It is not clear whether the reported obligations are the cause or the effect of doing volunteer work. Second, they do not tell us where the norms come from. Why do some people feel these obligations while others do not? As far as the first problem is concerned the solution lies in the proper design of the study using longitudinal data in which obligations can precede volunteerism and prior levels of volunteerism can be controlled. As far as the second problem is concerned, the answer lies in tracing norms back to their source. This means looking at the extent to which norms that might encourage volunteering are learned in social institutions such as the family, the church, and the school (Oesterle, Johnson, and Mortimer 2004:1129; Rossi 2001:116).

\section{Analytical Plan}

In this section we specify how we intend to analyze the relationship between religion, obligations, and volunteering. We use data gathered from the same panel of respondents in 1995 and 2005. The purpose of the analysis is to explain volunteering in 2005. Figure 1 outlines the theoretical model.

We assume that religiosity in the family of origin and education influence obligations, which in turn influence volunteering. The design is similar to that used by Matsuba, Hart, and Atkins (2007:892) in their study of the way in which obligations mediate the influence of psychological factors (e.g., personality traits, empathy) and social structure (e.g., family, social class) on volunteering, although their study is cross-sectional and ours is longitudinal.

The theoretical figure depicts in broad outlines the logic of the argument we use in this study. In the actual analysis we specify this model as follows. At the lefthand side of the model are depicted two exogenous variables: the religiosity of the home in which the respondent was raised and the respondent's educational attainment. The model then posits three mediating variables: volunteering, obligations, and religion. Volunteering is measured by a single item asking the respondent whether he/she volunteered for four different types of organization cause or charity. Obligations in 1995 are measured with two scales. "Civic obligations" measures people's feeling of responsibility to be involved in and make a contribution to the civic life of their community. For example, people are asked how strongly they feel obliged to perform duties such as sitting on a jury. "Altruistic obligations" measures more general feelings of responsibility for the welfare of others. For example, people are asked how strongly they feel it is their duty to perform acts of benefit to the community such as volunteering. Following Rossi (2001:292), we treat these two types of obligation as being independent but related, each with its own antecedents and consequences. Specifically, we expect to find that the effect of education on volunteering is more strongly mediated by civic than altruistic obligations because education is a better predictor of civic-a more secular set of activities - than altruistic obligations. Conversely, we expect to find that 


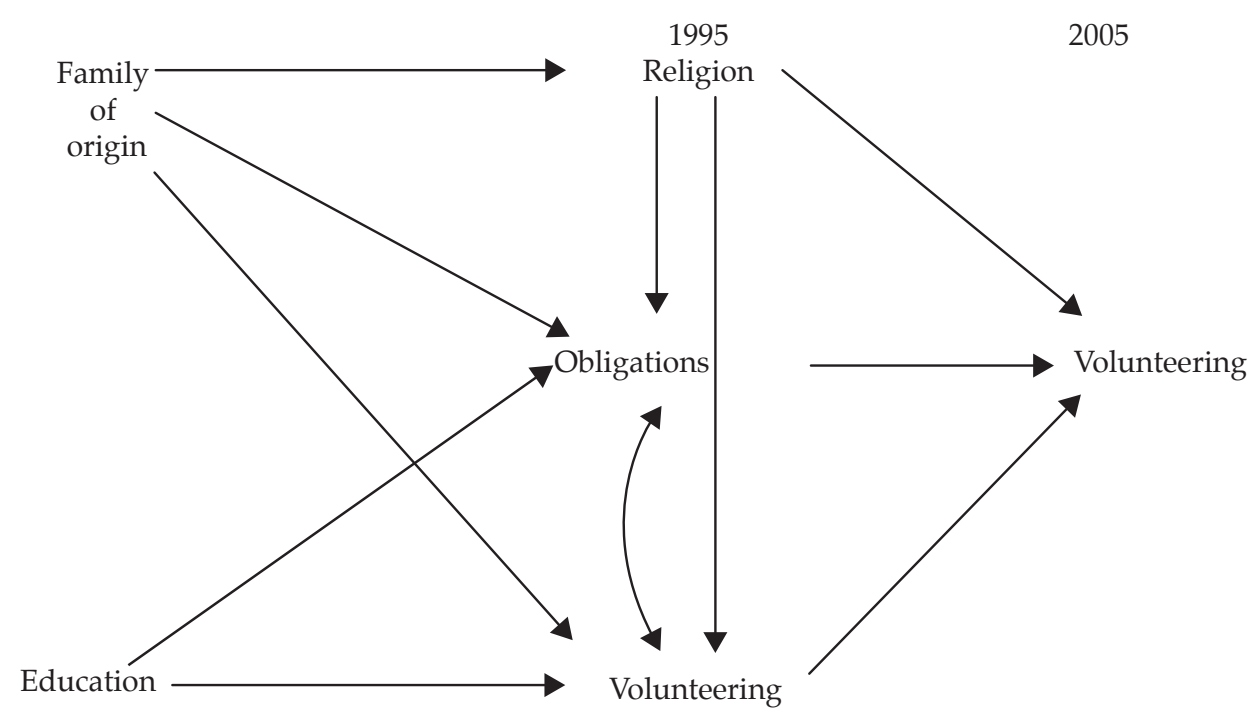

FIGURE 1

Theoretical Model

the effect of religion on volunteering is more strongly mediated by altruistic than civic obligations because the church is more oriented to general altruistic concerns than to more specific, secular civic activities. Simply put, people are more likely to absorb in church or through their religion the lesson that it is their responsibility to care for the welfare of others than that it is their responsibility to do jury duty.

As far as the measure of religiosity in 1995 is concerned, care must be taken to distinguish its different components. It is also important to control for religious affiliation. Our reasoning is as follows. It has long been recognized that "measuring religiosity with only one index is obviously misleading" (Wilson 1978:441). In addition to the more public and social aspects of being religious, such as attending worship services, engaging in collective rituals, and participating in activities organized by the congregation, there are more private aspects, such as saying prayers at home and watching religious programs on television, or simply being "spiritual" and practicing spiritual enhancement techniques such as meditation. In addition to these private practices, religiosity is also a personal and social identity, playing an important role in determining who one socializes with, how one educates one's children, and so on. Also included in the more private aspects of religion are the uses of religious ideas and practices to cope with the stresses of everyday life and to inform decision-making. Finally, and independent of both public and private aspects of religion, there is the "belief dimension": the values and beliefs taught by whatever religious tradition the individual commits to (Wilson 1978:443). Although religious beliefs vary widely and are not always professed in a coherent manner by individuals, sociologists typically try to capture the belief dimension by a question on denominational affiliation on the assumption 
that denominations are distinguishable by their teachings on basic religious ideas such as the meaning of salvation.

The multidimensional nature of religiosity poses a challenge to those who seek to determine its relationship to obligations and volunteering because "public religiosity and private religiosity can yield very different results, to say nothing of considering different religious affiliations" (Regnerus 2003:405). Furthermore, the different dimensions of religion might use different mechanisms to influence volunteering. That is, the reason they influence volunteering might be different. In their search for mechanisms, sociologists have focused mainly on the "public" side of religion, whereas psychologists have focused on the more "private" side of religion, on the way in which subjective aspects of religiosity such as values, motivations, attitudes, and beliefs encourage volunteering (Einolf 2011). Each discipline thus favors its own set of mediators to connect religion and volunteering. Sociologists emphasize the flow of information and influence through the social ties that arise out of the social life of the church. It is quite conceivable that obligations could be part of this information flow: norms taught by the church are more likely to be respected by those who are in weekly contact with fellow believers. But the mechanism is mainly structural: volunteering is the result of people meeting people or being recruited because they participate in a group. In the case of private religion there is very little structural connection to volunteerism: the subjective aspects of religion, such as identification, and the personal practices of religion, such as meditation, imply no wide or variegated social connections. In this case, the connection between religion and volunteering is almost entirely subjective, through psychological processes. Religion encourages volunteering because it changes the way people think about themselves and their relationship to others. In this case there is much more room for obligations to play a role. It is quite conceivable that people who think of themselves as religious and who believe that religion is important to them in their everyday life will internalize a duty to help others if this is what their religion teaches them. For example, being "spiritual" or having a "spiritual experiences" is often described as a feeling of "oneness" with others. This is just as likely to create a feeling of duty to help others as regularly attending church. Thus, Saroglou, Pichon, Trompette, Verschueren, and Dernelle (2005) found that spirituality was more closely related to prosocial behavior than more "public" aspects of religion, and Einolf (2011) found that "daily spiritual experiences" were positively related to volunteering even controlling for church attendance, their effect dissipating only when equally private aspects of religiosity, such as meditation, "mindfulness," and prayer, were added to the equation. We do not wish to argue that either private or public religion is a "better" or more robust predictor of volunteering but instead that they operate in different ways, through different mechanisms. Public religion works mainly through social connections; private religion works mainly through changing the way people think about themselves and the world around them. Of course, there is overlap between these two forms of religiosity and few people will practice one in the absence of the other, but by testing for the effects of one while controlling for the other, we hope to be able to detect differences in the way they operate. 
As far as religious beliefs are concerned, it is important to control for religious denomination because previous research has shown that the various churches and religious traditions in the United States vary in their teachings on, and institutional support for, volunteer work. A major study of religious congregations in the United States found that "mainline" Protestant congregations were the most likely to supply volunteers for at least one secular service organization, followed by Catholics, conservative Protestants, and African American Protestants (Ammerman 2002:154). In the National Congregations Study, Chaves (2004:53) found that congregations associated with evangelical denominations were less likely to sponsor social service programs than congregations associated with more liberal Protestant denominations or Catholic parishes. Surveys of individuals show that, controlling for socioeconomic status and frequency of church attendance, liberal Protestants are most likely to volunteer, followed by moderate Protestants and conservative Protestants. Jews are no more likely to volunteer than unaffiliated Americans. Catholics are actually less likely to volunteer than the unaffiliated (Musick and Wilson 2008:90). Other studies confirm this overall pattern. Most noticeably, evangelical Protestants, although they are very active in their own congregations, tend to volunteer at a lower rate than other Protestants, regardless of whether the work is secular or religious and regardless of frequency of church attendance (Beyerlein and Hipp 2006; Driskell, Lyon, and Embry 2008; Taniguchi and Thomas 2010; Wilson and Janoski 1995). Given these denominational differences in volunteer activity we believe it is important to control for this variable in our analysis.

Referring to Figure 1, the following assumptions are made when testing the hypothesis that obligations mediate the effect of religion and education on volunteering: parental religion is positively related to both 1995 public and 1995 private religion; public religion is positively related to 1995 and 2005 volunteering; private but not public religion is positively related to obligations in 1995; the effect of private religion on 2005 volunteering is mediated by 1995 volunteering and obligations; public and private religion are positively related; and the effect of education on 2005 volunteering is partially mediated by obligations and 1995 volunteering. Although we have argued above that private religion is more likely than public religion to affect volunteering "through" obligations, this mechanism does not exhaust all the possible ways in which private religion might influence volunteering, and we therefore allow, in the theoretical figure, for a direct effect of private religion in 1995 on volunteering in 2005.

To estimate the models we use Mplus 6.1. This program employs a MLM estimator (i.e., maximum likelihood parameter estimates with standard errors and a mean-adjusted chi-square test statistic) that accounts for non-normality of the endogenous variables even when at least one of them is a binary or ordered categorical measure (Muthén and Muthén 2010; Satorra and Bentler 2001).

\section{Data}

For data we use the national random-digit-dialing sample from the National Survey of Midlife in the United States (MIDUS) two-wave panel survey. Eligible respondents were noninstitutionalized, English-speaking adults in the coterminous 
United States between the ages of 25 and 74. The baseline national RDD sample was selected in 1995 from working telephone banks. Males between 65 and 74 were oversampled. The respondents participated in a computer-assisted telephone interview and also completed two self-administered questionnaire booklets mailed to their households. The 1995 sample consists of 3,487 respondents. The response rate estimates are 70 percent for the telephone interview, 86.8 percent for the completion of the self-administered questionnaires, and 60.8 percent for the combined response (i.e., $.700 \times .868$ ).

A follow-up survey of the original MIDUS sample was conducted between 2004 and 2006. The longitudinal retention rate of the national RDD sample is 71 percent, adjusting for mortality of the respondents. Multivariate logit regression of attrition revealed that those who failed to respond to the second wave were more likely to be nonwhite males with low education and income level (attrition in MIDUS is thoroughly analyzed in Radler and Ryff 2010). In light of the attrition rate between waves, we employ multiply-imputed data throughout our analyses (Arbuckle 1996; Graham 2009; Peugh and Enders 2004; Rubin 1976; Schafer 2003). This procedure creates parameter estimates by averaging the set of analyses on five multiply-imputed data sets, their standard errors being calculated on the basis of the average of the standard errors over the set of analyses and the between-analysis parameter estimation variation (Muthén and Muthén 2010). Specifically, the imputation procedure recovers missing values using the MICE (Multiple Imputation by Chained Equations) technique under the assumption of MAR (MissingAt-Random) (Royston 2005; Van Buuren, Boshuizen, and Knook 1999). In each chained equation, we used a set of predictors known to be related to the measure being imputed. The imputed data sets were also weighted to correct for unequal stratified probabilities of household and within-household respondent selection at the baseline. The sample weight post-stratified the sample to match the proportions of adults in the 1995 Current Population Survey with regard to age, gender, race, education, marital status, MSA (i.e., metropolitan and nonmetropolitan), and region (Northeast, Midwest, South, and West). The final sample count of the multiply-imputed data sets is 3,257, excluding 228 respondents who died between the two waves and two who are not covered by the weight variable.

\section{Measures}

\section{Endogenous Variables}

1995 and 2005 Volunteering. This was a binary measure where $0=$ not volunteered and 1 = volunteered for organizations related to health, education and youth work, politics, and any other cause or charity.

MIDUS uses two measures of a norm of social responsibility: altruistic and civic. The two measures are highly correlated, but factor analysis identifies them as related but separate dimensions of responsibility (Rossi 2004:582).

1995 Altruistic Obligation. The scale of altruistic obligation is a measure of normative predisposition using four items probing how much obligation (on a scale of 0 to 10) a respondent would feel in hypothetical situations: (1) paying more for your health care so that everyone had access to health care; (2) volunteering time 
and money to social issues you support; (3) collecting contributions for heart or cancer research if asked to do so; and (4) voting for a law that would help others worse than you but would increase your taxes. A factor analysis (not shown) indicated that the four indicators formed a single factor solution, and the scale reliability coefficient $(\alpha)$ of the four items was .80 . We therefore constructed a single scale ( 0 to 10 ) by summing the four items and dividing the sum by the number of items.

1995 Civic Obligation. A civic obligation scale is based on four items asking how much obligation (on a scale of 0 to 10) a respondent would feel in a series of hypothetical situations: (1) serving on a jury if called; (2) keeping fully informed about national news and public issues; (3) testifying in court about an accident you witnessed; and (4) voting in local and national elections. A factor analysis (not shown) indicated that the four items formed a single factor and the scale reliability coefficient $(\alpha)$ of the four items was .78. The items were summed and then divided by four to make a single scale (0 to 10$)$.

Private Religiosity. MIDUS contains three kinds of private religiosity measures on the basis of which we created a single latent factor. A summated scale of six items of religious identification (factor loading: 0.86) measures how salient the religious role is to the person. Another summated scale of two items (factor loading: 0.85) gauges the respondent's level of spirituality. Lastly, a summated scale of two items probing religious coping (factor loading: 0.89) shows how often the respondent uses religion as a source of comfort and guidance.

Public Religiosity. Two measures in MIDUS formed a single latent factor of public religiosity: one a question on frequency of attendance at religious or spiritual services (factor loading: 0.73) and the other a question on frequency of attendance at meetings of religious groups (factor loading: 0.73). (A table presenting the individual items in each measurement and the results of the factor analyses of private and public religiosity is available upon request.)

\section{Exogenous Variables}

Parental Religion. Parental religion was measured using a single item: How important was religion in your home when you were growing up? The response categories were $0=$ not at all important, $1=$ not very important, $2=$ somewhat important, and 3 = very important.

Education. We used a variable indicating the highest educational grade achieved by the respondent: (1) some grade school to some high school; (2) GED or high school diploma; (3) some college (no bachelor's degree); or (4) bachelor's degree or more advanced degree.

\section{Control Variables}

Several sociodemographic, socioeconomic, physical health status, and social network measures need to be controlled because they may confound the hypothesized causal relation between obligations and volunteering. All control variables are measured at baseline (1995).

Age. A continuous variable ranging between 20 and 74. [Eleven respondents $(0.3$ percent of the unimputed sample) gave their ages as less than 25, but we included them in the data analysis. We compared the SEM results with and without these outof-range respondents and found that they do not change the SEM path analyses.] 
Female. Gender was measured with a dichotomous variable where $1=$ female and $0=$ male.

White. This was measured with a dichotomous race variable where $1=$ white and $0=$ other.

Married. Marital status was measured with a dichotomous variable where $1=$ married and $0=$ not married.

Income. Income was measured using a thirty-one category measure of personal income in the past year.

Employed. Employment status was measured as $1=$ worked full-time (35+ hours/week) and $0=$ other (worked part-time [less than 35 hours/week]; no work or worked less than six months in the past year; or full-time student).

Physical Health. A self-evaluation of physical health status was scored as 1 = poor, 2 = fair, 3 = good, 4 = very good, and 5 = excellent.

Religious Tradition. Using the coding scheme in Steensland et al. (2000), religious tradition is sorted into the following categories: Mainline Protestant, Evangelical Protestant, Catholic, Jewish, Other, and None.

Contact Frequency with Friends. Respondents were asked how often they had any contact with friends, including visits, phone calls, letters, or electronic mails. The response categories were $1=$ never or hardly ever, $2=$ less than once a month, $3=$ about once a month, $4=$ two or three times a month, $5=$ about once a week, $6=$ several times a week, $7=$ about once a day, and $8=$ several times a day.

\section{RESULTS}

Table 1 displays the means for the variables used in the analysis. The percentages of MIDUS respondents who identified themselves as volunteers (39 percent in 1995 and 43 percent in 2005) are higher than the 28 percent reported in the annual Special Supplement on Volunteering of the Current Population Survey (CPS) (U.S. Bureau of Labor Statistics 2008). This might have something to do with the age limitations of MIDUS. At baseline it was restricted to respondents aged between 25 and 74, thus excluding the younger people included in the CPS (where the lower age limit is sixteen) and the oldest old. Both groups report low volunteer rates. The higher rates in MIDUS might also reflect greater nonresponse bias in MIDUS compared to that found in the CPS. It is well known that the lower the response rate, the greater the bias in favor of volunteers because they are more likely to agree to participate in surveys. The result is inflated estimates of the volunteer rate for which weighting adjustments cannot entirely correct. However, "bivariate or multivariate inferences about the relationship of volunteering (and likely other prosocial activities) to respondent characteristics are relatively immune to nonresponse bias" (Abraham, Helms, and Presser 2009:1162), and therefore it is unlikely that estimates of the mediating effects of obligations will be affected by the inflation found in MIDUS.

On average, MIDUS respondents reported feeling somewhat more responsibility for civic than altruistic acts. This might be due to the fact that, as noted above, the altruistic obligations can seem more onerous than the civic acts. The average respondent said religion was "somewhat" important in their home when they were growing up. Public and private religion had means close to 0 and standard 
TABLE 1

Variables in the Analyses (Multiply-Imputed Data Sets, Sample Weighted)

\begin{tabular}{lrcc}
\hline Measure & $M$ & $(S D)$ & Range \\
\hline Final endogenous variables (2005) & & & \\
$\quad$ Volunteering & 0.43 & $(0.50)$ & $0-1$ \\
Intermediate endogenous variables (1995) & & & \\
$\quad$ Volunteering & 0.39 & $(0.49)$ & $0-1$ \\
Altruistic obligation & 5.79 & $(2.18)$ & $0-10$ \\
Civic obligation & 7.53 & $(2.00)$ & $0-10$ \\
Public religion (factor) & -0.03 & $(0.72)$ & $-2.70-2.20$ \\
$\quad$ Private religion (factor) & -0.03 & $(1.00)$ & $-4.15-2.86$ \\
Exogenous variables (1995) & & & \\
Parental religion & 2.17 & $(0.87)$ & $0-3$ \\
Education & 2.80 & $(0.96)$ & $1-4$ \\
Controls (1995) & & & \\
Demographic, socioeconomic, health & & & \\
$\quad$ Age & 42.83 & $(12.48)$ & $20-74$ \\
$\quad$ Female & 0.55 & $(0.50)$ & $0-1$ \\
$\quad$ White & 0.86 & $(0.34)$ & $0-1$ \\
$\quad$ Married & 0.68 & $(0.47)$ & $0-1$ \\
$\quad$ Income & 17.81 & $(9.79)$ & $1-31$ \\
$\quad$ Employed & 0.69 & $(0.46)$ & $0-1$ \\
$\quad$ Physical health & 3.51 & $(0.97)$ & $1-5$ \\
Religious tradition & & & \\
$\quad$ Evangelical Protestant (reference) & 0.32 & $(0.47)$ & $0-1$ \\
$\quad$ Mainline Protestant & 0.23 & $(0.42)$ & $0-1$ \\
Catholic & 0.26 & $(0.44)$ & $0-1$ \\
$\quad$ Jewish & 0.02 & $(0.15)$ & $0-1$ \\
Other & 0.06 & $(0.24)$ & $0-1$ \\
$\quad$ None & 0.11 & $(0.31)$ & $0-1$ \\
Social network & & & \\
$\quad$ Contact frequency with friends & 5.64 & $(1.72)$ & $1-8$ \\
\hline
\end{tabular}

Note: $N=3,257$.

deviations close to 1 as they were produced by factor analysis. As far as education is concerned, the average MIDUS respondent did not have any college experience. The mean age at baseline was 43, 55 percent of the respondents were women, 86 percent were white, just over two-thirds (68 percent) were married, and 69 percent were working for pay. On average they rated their health as "good" to "very good." Nearly a third of MIDUS respondents belonged to denominations classified as Evangelical Protestant. About equal proportions of respondents belonged to mainline Protestant denominations and Catholic churches. The average MIDUS respondent had contact with friends once a week.

In pairwise correlations parental religion is positively correlated with both altruistic and civic obligation and with both public and private religion. (A table showing the correlations is available upon request.) It is more strongly correlated with 1995 volunteering than 2005 volunteering. Education is positively correlated 
with both 1995 and 2005 volunteering, both types of obligation and both types of religion. Both public and private religiosities are positively correlated with both 1995 and 2005 volunteering, as are both types of obligation. An Evangelical Protestant affiliation increases the chances of volunteering, as does being Mainline Protestant, but Catholics are less likely to be volunteers. Jews feel more altruistic obligation, whereas "Other" affiliations and those with no affiliation feel less. Mainline Protestants feel more civic obligation and nonaffiliates less.

The first stage of the analysis is to see if parental religion and education explain variation in obligations. The estimated structural equation models are shown in Table 2. For each obligation the first model shows the results without 1995 religion and the second shows the results with 1995 religion included. Education is a significant source of both obligations, somewhat more so for civic, and its effect is not altered by the inclusion of the 1995 religion variables. Although parental religion has a significant effect on both types of obligation in Model 1, it becomes insignificant with the introduction of the two 1995 religion variables. The coefficients for those variables show that the private dimension of religion is responsible for this. In other words, the effect of parental religion on obligations is fully mediated or absorbed by the respondent's own private religiosity. The pattern is the same for both types of obligation. The control variable coefficients shown in Model 2 indicate that older people feel a stronger sense of obligation, particularly of the civic kind. Women feel more obligated than men, particularly altruistically, and race makes a difference only in the case of altruistic obligations. Frequency of contact with friends has a positive influence on both kinds of obligation and married people feel more civically obligated. Compared to Evangelicals, Jews are more likely to feel altruistic obligations: this is the only affiliation effect in the obligations model.

The discussion now turns to the full mediation argument where 2005 volunteering is the outcome variable. Table 3 (Model 1) and Figure 2 show the SEM estimates for 2005 volunteering where altruistic obligation is the mediator variable. Only the pathways with significant coefficients are shown in the figure and the control variables are not displayed even though they were employed for the four endogenous variables.

Altruistic obligation has a positive effect on volunteering ten years later (.07, $p<.01)$, controlling for baseline volunteering and several other confounders known to determine adult volunteering, including education, religious affiliation, and social networks. The link between altruistic obligation and volunteering is also indicated by the strong cross-sectional correlation of the two measures in 1995 $(.20, p<.001)$. Public religion in 1995 predicts 2005 volunteering, but private religion does not have a direct effect: its influence on 2005 volunteering is mediated partly by altruistic obligations and partly by 1995 volunteering. Education has a direct effect on 2005 volunteering, but it also has an indirect effect through altruistic obligation, despite the fact that it also has a positive effect on 1995 volunteering, a quite impressive demonstration of the independent influence of social norms. The first column in Table 3 reports the coefficients for the control variables, measured in 1995. Older people are less likely to volunteer, whereas women and those who are married and who rate their health as good are more likely to volunteer. There are no denominational differences in volunteering. 
TABLE 2

SEM of 1995 Altruistic and Civic Obligations Using Multiply-Imputed Data

\begin{tabular}{|c|c|c|c|c|}
\hline & \multicolumn{2}{|c|}{$\begin{array}{l}1995 \text { Altruistic } \\
\text { Obligation }\end{array}$} & \multicolumn{2}{|c|}{$\begin{array}{l}1995 \text { Civic } \\
\text { Obligation }\end{array}$} \\
\hline & Model 1 & Model 2 & Model 1 & Model 2 \\
\hline \multicolumn{5}{|l|}{ Main explanatory measures } \\
\hline Parental religion & $.06^{*}$ & .03 & $.05^{*}$ & .02 \\
\hline Public religion (factor) & - & .00 & - & .01 \\
\hline Private religion (factor) & - & $.12^{* * *}$ & - & $.13^{* * *}$ \\
\hline Education & $.06^{* *}$ & $.05^{* *}$ & $.12^{* * *}$ & $.11^{* * *}$ \\
\hline \multicolumn{5}{|c|}{ Controls } \\
\hline \multicolumn{5}{|l|}{ Demographic, socioeconomic, health } \\
\hline Age & $.14^{* * *}$ & $.13^{* * *}$ & $.24^{* * *}$ & $.23^{* * *}$ \\
\hline Female & $.13^{* * *}$ & $.11^{* * *}$ & $.06^{* *}$ & .04 \\
\hline White & $-.11^{* * *}$ & $-.11^{* * *}$ & -.01 & -.00 \\
\hline Married & -.01 & -.01 & $.07^{* *}$ & $.06^{* *}$ \\
\hline Income & -.03 & -.02 & .04 & .04 \\
\hline Employed & .01 & .01 & -.00 & -.00 \\
\hline Physical health & .01 & .00 & .04 & .03 \\
\hline \multicolumn{5}{|l|}{$\begin{array}{l}\text { Religious tradition } \\
\text { (ref.: Evangelical Protestant) }\end{array}$} \\
\hline Mainline Protestant & -.00 & .01 & .01 & .02 \\
\hline Catholic & -.01 & .01 & -.00 & .01 \\
\hline Jewish & .04 & $.05^{*}$ & -.00 & .01 \\
\hline Other & -.03 & -.03 & -.04 & -.04 \\
\hline None & -.02 & .02 & -.03 & .00 \\
\hline \multicolumn{5}{|l|}{ Social network } \\
\hline Contact frequency with friends & $.08^{* * *}$ & $.08^{* * *}$ & $.10^{* * *}$ & $.09^{* * *}$ \\
\hline \multicolumn{5}{|l|}{ Model fit indices } \\
\hline Chi-square & 0.00 & 0.00 & 0.00 & 0.00 \\
\hline CFI & 1.00 & 1.00 & 1.00 & 1.00 \\
\hline TLI & 1.00 & 1.00 & 1.00 & 1.00 \\
\hline RMSEA & 0.00 & 0.00 & 0.00 & 0.00 \\
\hline$R^{2}$ & .07 & .08 & .10 & .11 \\
\hline$N$ & 3,257 & 3,257 & 3,257 & 3,257 \\
\hline
\end{tabular}

Note: All estimates are standardized; CFI = Comparative Fit Index; TLI = Tucker-Lewis Index; RMSEA = Root Mean Square Error of Approximation; MLM (Maximum Likelihood parameter estimates with standard errors and a Meanadjusted chi-square test statistic) estimator applied due to the nonnormality of outcome measures; the analyses employed five weighted multiply-imputed data sets. ${ }^{*} p<.05 ;{ }^{* *}<.01 ; * * * p<.001$ (two-tailed).

Table 3 (Model 2) shows the SEM estimates for 2005 volunteering where civic obligation is the mediating variable. Figure 3 displays the results of the path analysis. Only pathways with significant coefficients are shown and the control variables are not shown. Because of the similarities between the two analyses (e.g., the influence of public religion on volunteering), we will focus on the mediation hypothesis. Most importantly, civic obligations have a positive effect on 2005 volunteering, net of the effect of prior volunteering and of the direct effect on volunteering of 
TABLE 3

SEM of 2005 Volunteering Using Multiply-Imputed Data

\begin{tabular}{|c|c|c|}
\hline & \multicolumn{2}{|c|}{$\begin{array}{c}\text { Endogenous Variable: } 2005 \\
\text { Volunteering }\end{array}$} \\
\hline & Model 1 & Model 2 \\
\hline \multicolumn{3}{|l|}{ Main explanatory measures } \\
\hline Altruistic obligation & $.07^{* *}$ & - \\
\hline Civic obligation & - & $.10^{*}$ \\
\hline 1995 volunteering & $.12^{* * *}$ & $.12^{* * *}$ \\
\hline Parental religion & .03 & .03 \\
\hline Public religion (factor) & $.07^{*}$ & $.07^{*}$ \\
\hline Private religion (factor) & .02 & .02 \\
\hline Education & $.19^{* * *}$ & $.18^{* * *}$ \\
\hline \multicolumn{3}{|l|}{ Controls } \\
\hline \multicolumn{3}{|l|}{ Demographic, socioeconomic, health } \\
\hline Age & $-.07^{* *}$ & $-.09^{* * *}$ \\
\hline Female & $.07^{* *}$ & $.07^{* *}$ \\
\hline White & .03 & .02 \\
\hline Married & $.09^{* *}$ & $.08^{* *}$ \\
\hline Income & .04 & .03 \\
\hline Employed & .01 & .01 \\
\hline Physical health & $.04^{*}$ & .04 \\
\hline \multicolumn{3}{|l|}{ Religious tradition (ref.: Evangelical Protestant) } \\
\hline Mainline Protestant & .03 & .02 \\
\hline Catholic & -.01 & -.02 \\
\hline Jewish & .02 & .02 \\
\hline Other & .01 & .02 \\
\hline None & .01 & .01 \\
\hline \multicolumn{3}{|l|}{ Social network } \\
\hline Contact frequency with friends & .01 & .00 \\
\hline \multicolumn{3}{|l|}{ Correlations } \\
\hline Altruistic obligation with 1995 Volunteering & $.20^{* * *}$ & - \\
\hline Civic obligation with 1995 Volunteering & - & $.16^{* * *}$ \\
\hline Public religion with private religion & $.57^{* * *}$ & $.57^{* * *}$ \\
\hline \multicolumn{3}{|l|}{ Model fit indices } \\
\hline Chi-square & 0.00 & 0.00 \\
\hline CFI & 1.00 & 1.00 \\
\hline TLI & 1.00 & 1.00 \\
\hline RMSEA & 0.00 & 0.00 \\
\hline$R^{2}$ & .13 & .13 \\
\hline$N$ & 3,257 & 3,257 \\
\hline
\end{tabular}

Note: All estimates are standardized; CFI = Comparative Fit Index; TLI = Tucker-Lewis Index; RMSEA = Root Mean Square Error of Approximation; MLM (Maximum Likelihood parameter estimates with standard errors and a meanadjusted chi-square test statistic) estimator applied due to the nonnormality of outcome measures; the analyses employed five weighted multiply-imputed data sets. ${ }^{*} p<.05 ;{ }^{* *} p<.01 ;{ }^{* * *} p<.001$ (two-tailed).

education and public religion. The model shows the same pattern as that seen in the analysis of altruistic obligations: the effect of parental religion is not direct but funneled through private religion. Education has a direct effect on 2005 volunteering and an indirect effect funneled through civic obligation and 1995 volunteering. 


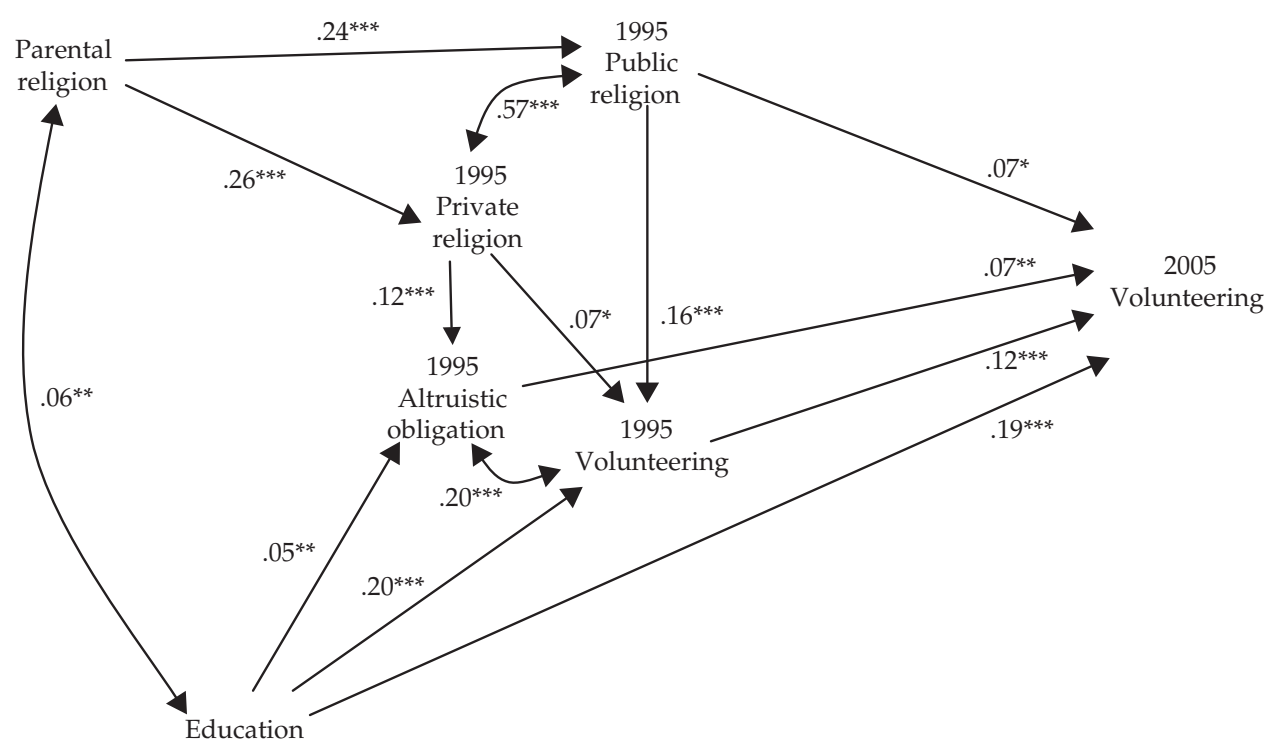

Note: $N=3,257$. All estimates are standardized. Control variables were employed but not displayed in the figure for simple presentation; see Tables 2 and 3 for the effects of control measures. Insignificant paths are not displayed either. Model fits: CFI (Comparative Fit Index) =1.00, TLI (Tucker-Lewis Index) =1.00, RMSEA (Root Mean Square Error of Approximation $)=.00 . R^{2}(2005$ Volunteering $)=.13, R^{2}(1995$ Volunteering $)=.12, R^{2}(1995$ Altruistic obligation $)=.08$, $R^{2}(1995$ Public religion $)=.21, R^{2}(1995$ Private religion $)=.24$. MLM (Maximum Likelihood parameter estimates with standard errors and a Mean-adjusted chi-square test statistic) estimator applied due to the nonnormality of endogenous measures. The analyses employed five weighted multiply-imputed data sets.

${ }^{*} p<.05 ;{ }^{* *} p<.01 ;{ }^{* * *} p<.001$ (two-tailed).

\section{FIGURE 2}

SEM Path Analysis of Altruistic Obligation and Volunteering Using Multiply-Imputed Data

The second column in Table 3 shows the coefficients for the control variables in the civic obligation model. They are virtually identical to those shown in the first column, the only difference being that the physical health coefficient is no longer significant.

A more precise estimate of the mediation effects of obligations is given by calculating the total, direct, and indirect effects of parental religion and education on 2005 volunteering. The results of this analysis are shown in Tables 4-1 and 4-2.

As measured by the standardized total effects, both parental religion and education contribute to volunteerism, although education has much stronger influence (about .230) than parental religion (.057). As shown in Table 4-1, parental religion affects volunteering in 2005 only indirectly. One pathway is through public religion. Religious parents increase the chances of their children volunteering as adults because they socialize them into regular church attendance and participation in church activities, and this has a direct effect on volunteering later in life. Public religion is also involved in another significant pathway. By raising religious children, parents are in fact raising people likely to volunteer-as seen in the correlation between 1995 religiosity of both types and 1995 volunteering. Although we can never be sure that the relationship between 1995 and 2005 volunteering is not partly due to unmeasured variables that affect volunteering in 


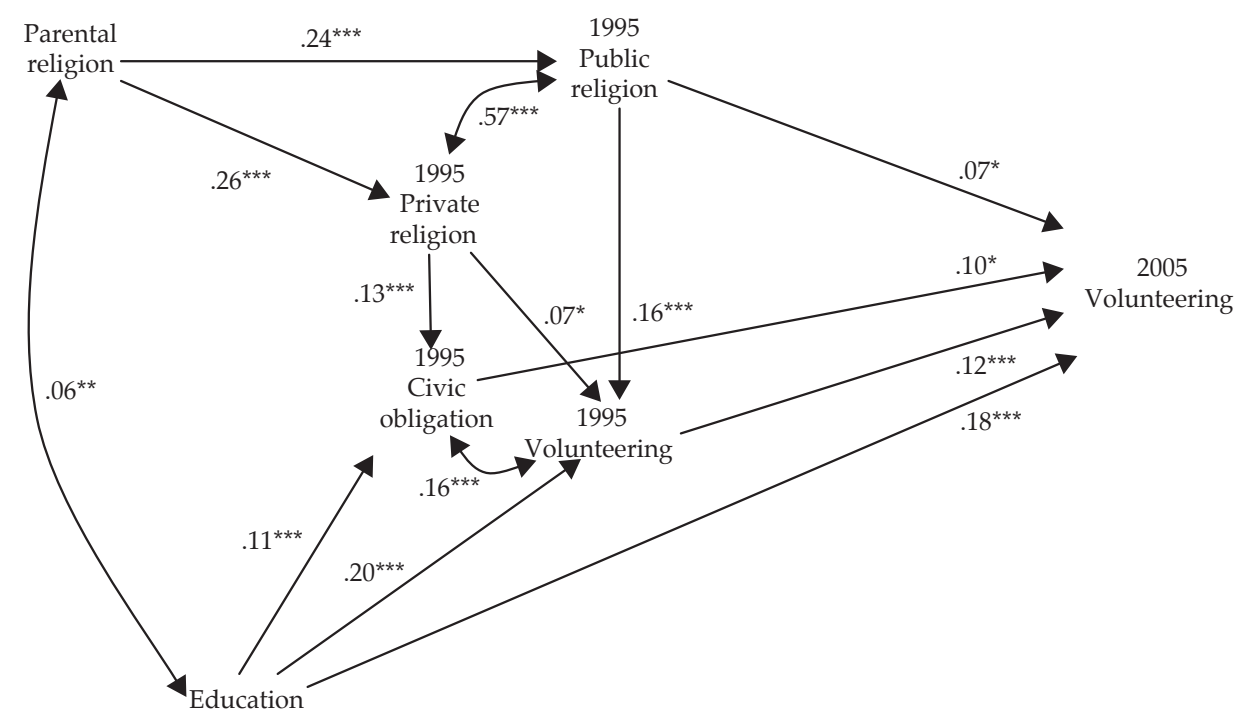

Note: $N=3,257$. All estimates are standardized. Control variables were employed but not displayed in the figure for simple presentation; see Tables 2 and 3 for the effects of control measures. Insignificant paths are not displayed either. Model fits: CFI (Comparative Fit Index) $=1.00$, TLI (Tucker-Lewis Index) $=1.00$, RMSEA (Root Mean Square Error of Approximation $)=.00 . R^{2}(2005$ Volunteering $)=.13, R^{2}(1995$ Volunteering $)=.12, R^{2}(1995$ Civic obligation $)=.11, R^{2}$ $(1995$ Public religion $)=.21, R^{2}(1995$ Private religion $)=.24$. MLM (Maximum Likelihood parameter estimates with standard errors and a Mean-adjusted chi-square test statistic) estimator applied due to the nonnormality of endogenous measures. The analyses employed five weighted multiply-imputed data sets.

${ }^{*} p<.05 ;{ }^{* *} p<.01 ;{ }^{* * *} p<.001$ (two-tailed).

\section{FIGURE 3}

SEM Path Analysis of Civic Obligation and Volunteering Using Multiply-Imputed Data

both years, the experience of volunteering in 1995 carries over into volunteering 10 years later. Finally, there is the pathway through obligations: religious parents tend to raise more religious offspring and religious offspring are more likely to feel obligated to help others. These felt obligations, in turn, motivate volunteering in 2005. However, only the pathway through private religion is significant because public religion is not associated with altruistic obligations in the structural equation model.

The pattern of direct, indirect, and total effects for civic obligation shown in the bottom half of Table 4-1 is virtually identical to that shown for altruistic obligations. Table 4-2 shows the direct, indirect, and total effects of education where the mediator is altruistic obligations (top half) and civic obligations (bottom half).

As noted earlier, the total effect of education on volunteering is much stronger than parental religion. There are notable differences from the parental religion models. In both the top and bottom halves of the table significant direct effects of education on volunteering are shown. Although previous experience is an "asset" as far as volunteering is concerned, between two people with the same level of experience, the more highly educated is the most likely to be volunteering in 2005. And as Table 4-2 shows, education has already made a contribution to 2005 volunteering by increasing the likelihood that a person would have 
TABLE 4-1

Standardized Total, Direct, and Indirect Effects of Parental Religion on 2005 Volunteering

\begin{tabular}{cc}
\hline Parental Religion to 2005 Volunteering & $\beta$ \\
\hline Parental religion to 2005 volunteering (mediator:1995 altruistic obligation) & \\
PR to $2005 \mathrm{~V}$ (Total) & $0.057^{* *}$ \\
$\mathrm{PR} \rightarrow 2005 \mathrm{~V}$ (Direct) & 0.027 \\
$\mathrm{PR} \rightarrow 1995 \mathrm{~V} \rightarrow 2005 \mathrm{~V}$ (Indirect) & -0.002 \\
$\mathrm{PR} \rightarrow 1995$ PubR $\rightarrow 2005 \mathrm{~V}$ (Indirect) & $0.016^{* *}$ \\
$\mathrm{PR} \rightarrow 1995$ PrivR $\rightarrow 2005 \mathrm{~V}$ (Indirect) & 0.005 \\
$\mathrm{PR} \rightarrow \underline{1995 \mathrm{AO} \rightarrow 2005 \mathrm{~V} \text { (Indirect) }}$ & 0.002 \\
$\mathrm{PR} \rightarrow 1995$ PubR $\rightarrow 1995 \mathrm{~V} \rightarrow 2005 \mathrm{~V}$ (Indirect) & $0.005^{* * *}$ \\
$\mathrm{PR} \rightarrow 1995$ PrivR $\rightarrow 1995 \mathrm{~V} \rightarrow 2005 \mathrm{~V}$ (Indirect) & $0.002^{* *}$ \\
$\mathrm{PR} \rightarrow 1995$ PubR $\rightarrow \underline{1995 \mathrm{AO}} \rightarrow 2005 \mathrm{~V}$ (Indirect) & 0.000 \\
$\mathrm{PR} \rightarrow 1995$ PrivR $\rightarrow \underline{1995 \mathrm{AO}} \rightarrow 2005 \mathrm{~V}$ (Indirect) & $0.002^{* *}$
\end{tabular}

Parental religion to 2005 volunteering (mediator:1995 civic obligation)

\begin{tabular}{|c|c|}
\hline PR to 2005 V (Total) & $0.057^{* *}$ \\
\hline$P R \rightarrow 2005$ V (Direct) & 0.028 \\
\hline $\mathrm{PR} \rightarrow 1995 \mathrm{~V} \rightarrow 2005 \mathrm{~V}$ (Indirect) & -0.002 \\
\hline PR $\rightarrow 1995$ PubR $\rightarrow 2005$ V (Indirect) & $0.016^{* *}$ \\
\hline PR $\rightarrow 1995$ PrivR $\rightarrow 2005$ V (Indirect) & 0.004 \\
\hline $\mathrm{PR} \rightarrow \underline{1995 \mathrm{CO}} \rightarrow 2005 \mathrm{~V}$ (Indirect) & 0.001 \\
\hline PR $\rightarrow 1995$ PubR $\rightarrow 1995$ V $\rightarrow 2005$ V (Indirect) & $0.005^{* * *}$ \\
\hline PR $\rightarrow 1995$ PrivR $\rightarrow 1995$ V $\rightarrow 2005$ V (Indirect) & $0.002^{* *}$ \\
\hline $\mathrm{PR} \rightarrow 1995 \mathrm{PubR} \rightarrow \underline{1995 \mathrm{CO}} \rightarrow 2005 \mathrm{~V}$ (Indirect) & 0.000 \\
\hline $\mathrm{PR} \rightarrow 1995$ Priv $\mathrm{R} \rightarrow 1995 \mathrm{CO} \rightarrow 2005 \mathrm{~V}$ (Indirect) & $0.003^{* * *}$ \\
\hline
\end{tabular}

Note: $\mathrm{PR}=$ Parental Religion; $\mathrm{V}=$ Volunteering; PubR = Public Religion; PrivR = Private Religion; $\mathrm{AO}=$ Altruistic Obligation; $\mathrm{CO}=$ Civic Obligation. The SEM software (Mplus) does not provide indirect effects estimates when using multiply-imputed data; thus, $\beta$ (standardized) coefficients were averaged across five multiply-imputed data; $z$ scores were also averaged across the five data sets to produce two-tailed $p$ values for $\beta$ estimates. ${ }^{*} p<.05 ; * * p<.01 ; * * *<.001$ (two-tailed).

prior experience as a volunteer both directly to 1995 volunteering and indirectly to 1995 volunteering through religiosity of both kinds. Finally, Table 4-2 shows quite clearly the mediating role that obligations play in connecting education to volunteering. The second row of each half of the table shows that most of the total effect of education on volunteering is attributable to its direct, unmediated influence, followed by its effect "through" 1995 volunteering. Within the confines of these models then, education's effect on volunteering has rather little to do with either religion or obligations. But there are additional, indirect effects. First, educated people tend to feel a greater sense of both altruistic and civic obligation, and this is turn leads to both 1995 and 2005 volunteering. Second, 
TABLE 4-2

Standardized Total, Direct, and Indirect Effects of Education on 2005 Volunteering.

Education to 2005 Volunteering

$\beta$

Education to 2005 volunteering (mediator:1995 altruistic obligation)

$\begin{array}{ll}\mathrm{E} \text { to } 2005 \mathrm{~V} \text { (Total) } & 0.230^{* * *} \\ \mathrm{E} \rightarrow 2005 \mathrm{~V} \text { (Direct) } & 0.192^{* * *} \\ \mathrm{E} \rightarrow 1995 \mathrm{~V} \rightarrow 2005 \mathrm{~V} \text { (Indirect) } & 0.023^{* * *} \\ \mathrm{E} \rightarrow 1995 \mathrm{PubR} \rightarrow 2005 \mathrm{~V} \text { (Indirect) } & 0.006^{*} \\ \mathrm{E} \rightarrow 1995 \text { PrivR } \rightarrow 2005 \mathrm{~V} \text { (Indirect) } & 0.001 \\ \mathrm{E} \rightarrow \underline{1995 \mathrm{AO} \rightarrow 2005 \mathrm{~V} \text { (Indirect) }} & 0.004^{*} \\ \mathrm{E} \rightarrow 1995 \mathrm{PubR} \rightarrow 1995 \mathrm{~V} \rightarrow 2005 \mathrm{~V} \text { (Indirect) } & 0.002^{* * *} \\ \mathrm{E} \rightarrow 1995 \text { PrivR } \rightarrow 1995 \mathrm{~V} \rightarrow 2005 \mathrm{~V} \text { (Indirect) } & 0.001^{*} \\ \mathrm{E} \rightarrow 1995 \text { PubR } \rightarrow \underline{1995 \mathrm{AO}} \rightarrow 2005 \mathrm{~V} \text { (Indirect) } & 0.000 \\ \mathrm{E} \rightarrow 1995 \text { PrivR } \rightarrow \underline{1995 \mathrm{AO}} \rightarrow 2005 \mathrm{~V} \text { (Indirect) } & 0.001^{*}\end{array}$

Education to 2005 volunteering (mediator:1995 civic obligation)

$\begin{array}{ll}\mathrm{E} \text { to } 2005 \mathrm{~V} \text { (Total) } & 0.229^{* * *} \\ \mathrm{E} \rightarrow 2005 \mathrm{~V} \text { (Direct) } & 0.184^{* * *} \\ \mathrm{E} \rightarrow 1995 \mathrm{~V} \rightarrow 2005 \mathrm{~V} \text { (Indirect) } & 0.023^{* * *} \\ \mathrm{E} \rightarrow 1995 \mathrm{PubR} \rightarrow 2005 \mathrm{~V} \text { (Indirect) } & 0.006^{*} \\ \mathrm{E} \rightarrow 1995 \text { PrivR } \rightarrow 2005 \mathrm{~V} \text { (Indirect) } & 0.001 \\ \mathrm{E} \rightarrow \underline{1995 \mathrm{CO} \rightarrow 2005 \mathrm{~V} \text { (Indirect) }} & 0.011^{* * *} \\ \mathrm{E} \rightarrow 1995 \text { PubR } \rightarrow 1995 \mathrm{~V} \rightarrow 2005 \mathrm{~V} \text { (Indirect) } & 0.002^{* * *} \\ \mathrm{E} \rightarrow 1995 \text { PrivR } \rightarrow 1995 \mathrm{~V} \rightarrow 2005 \mathrm{~V} \text { (Indirect) } & 0.001^{*} \\ \mathrm{E} \rightarrow 1995 \text { PubR } \rightarrow \underline{1995 \mathrm{CO}} \rightarrow 2005 \mathrm{~V} \text { (Indirect) } & 0.000 \\ \mathrm{E} \rightarrow 1995 \text { PrivR } \rightarrow \underline{1995 \mathrm{CO}} \rightarrow 2005 \mathrm{~V} \text { (Indirect) } & 0.001^{* *}\end{array}$

Note: $\mathrm{E}$ = Education; $\mathrm{V}$ = Volunteering; PubR = Public Religion; PrivR = Private Religion; $\mathrm{AO}$ = Altruistic Obligation; $\mathrm{CO}=$ Civic Obligation. The SEM software (Mplus) does not provide indirect effects estimates when using multiplyimputed data; thus, $\beta$ (standardized) coefficients were averaged across five multiply-imputed data; $z$ scores were also averaged across the five data sets to produce two-tailed $p$ values for $\beta$ estimates. ${ }^{*} p<.05 ;{ }^{* *} p<.01 ;{ }^{* * *} p<.001$ (two-tailed).

educated people are more religious. We have already seen that public religion encourages volunteering directly and some of the effect of education is thus carried through its effect on public religion. Third, the positive influence of education on private religion leads in turn to higher scores on each obligation measure, which in turn leads to volunteering. However, there is no pathway from education through public religion and obligations to volunteering because, as shown in Table 2, public religion has no effect on obligations.

In summary, obligations do influence volunteering. Controlling for prior volunteering experience (i.e., controlling for selection effects) the structural coefficient for altruistic obligations is $0.07(p<.01)$ and for civic obligations it is $0.10(p<.05)$. 
According to chi-square tests of equality constraint, it is likely that civic obligation has a greater effect on 2005 volunteering than altruistic obligation (see the Appendix). Despite the fact that the altruistic obligation scale includes a question on volunteer work, it does not predict volunteering as well as the civic obligation scale. The altruistic measure is designed to be broader in scope, more humanitarian, and this type of obligation can be met by a wide variety of forms of altruism, such as helping a neighbor or donating money to a cause. Second, obligations mediate and therefore help explain why and how religion and education influence volunteering. The contribution is not large but should not be ignored. In the models we estimated, altruistic and civic obligations comprise 14 percent (7 percent for each type of obligation) of the total effect originating in parental religion. Out of the total effect of education on volunteering, the indirect effects attributable to civic obligation is 5.2 percent compared to 2.2 percent for altruistic obligation. Earlier, we indicated that we expected to find the effect of education on volunteering to be more strongly mediated by civic than altruistic obligations because education is a better predictor of civic-a more secular set of activities - than altruistic obligations. This appears to be true. But we also said we expected that altruistic obligations would be a more important mediator for parental religion than civic obligations, but this was not true.

\section{DISCUSSION}

In his book on civic engagement, Campbell (2006:191) observed that "a sense of civic obligation has been largely ignored as a subject of serious research." The same statement could be made about its neglect in the study of volunteerism. Contrary to the claim of those sociologists who argue that norms are usually expressed at such a general level that they are either too imprecise to provide guidance or easily avoided because they do not apply to specific situations and contrary to those who argue that normative theories are little more than truisms adding little to our understanding of the causes of human behavior, we have shown that norms do make a difference.

In this study we investigate the possibility that two of the most powerful socialization institutions in society-religion and education-affect volunteering through the teaching of obligations. Drawing on a developmental perspective, we looked for ways in which early religious experiences would have influenced adult volunteering using a measure of the importance attached to religion by one's parents when one was growing up. We also placed education in a developmental framework, casting it as an early influence on later religiosity and obligations. We found that recalled parental religion had no direct effect on what MIDUS respondents (whose mean age was 43 in 1995) were doing in the way of volunteer work. Nor did it have any direct effect on volunteering 10 years later. And children reared in religious homes felt no more obliged to help others or serve their community than the children of parents for whom religion was not important. This did not mean, however, that early family religiosity was inconsequential. The reason is that ongoing religiosity of the respondent in 1995 had "absorbed" all the effect of parental religion. (Recall that parental religion does have a positive effect on obligations until 1995 religiosity is entered into the model.) And it was this pathway 
that links the family of origin to the adults in the survey. It is because they are now religious that they feel more obliged to help, and they are more religious now because their parents were religious when they were growing up.

In an original contribution to this field, we separated religion into two components in order to examine how norms might explain why it is so influential. We found that public religion mediates the effect of parental religion on volunteering without, however, using social norms to do so. Obligations do not explain why public religion encourages volunteer work. This provides support to the structural theory that religiosity can lead to volunteering by fostering social contacts and social ties. But this does not exhaust the influence of religion on volunteering because private religiosity has a positive effect on obligations. Indeed, private religiosity had only a mediated effect on 2005 volunteering. This study therefore underlines the importance of taking the several dimensions of religion into account.

Education had a positive direct effect on both types of obligation, although more so for civic than altruistic. The analysis therefore helps solve the puzzle that has confronted social scientists as to why education has such a robust effect on volunteerism. The fact that education has a stronger effect on civic than altruistic obligation might have something to do with the more secular and more "public" acts listed in the civic obligation scale. Education not only raises awareness of civic affairs but also increases the likelihood that helping deal with social problems requires being active in the public sphere-for instance, feeling a responsibility to deal with homelessness as well as the homeless person. Schooling educates us to ask not only "How am I doing?" but also "How are we doing?" (Galston 2007:110). This difference between the two obligations should not be exaggerated. The altruism scale includes a reference to supporting laws, but the emphasis is on the sacrifice involved if the law was passed and not the policy implications of passing new laws. Although there is justified skepticism about the efficacy of "civics education" and "service learning" in educational institutions, there is also convincing evidence that schools can teach civic obligations if the curriculum includes "exposure to the wider political and social context of class material and opportunities to engage in political action" (Riedel 2002:518).

The analysis also shows that education has a strong direct effect on volunteering, which raises the question of what other mechanisms could explain its positive effect. Some of these are discussed in Musick and Wilson (2008:126). They include subjective dispositions such as self-efficacy, wider social networks, and "ability signaling," as when organizations looking for volunteers use educational credentials as an indicator of readiness to volunteer. An anonymous reviewer has pointed out that the higher incomes of the more educated might also help explain their volunteerism, as well as the likelihood that they have jobs with more flexible hours. A recent study shows that full-time workers who are paid on an hourly basis-more typical of lower status jobs held by the poorly educated-volunteer less than those who are paid on a monthly basis-more typical of the managerial and professional workers who have college degrees (DeVoe and Pepper 2007:783).

Although obligations do influence volunteering, their effect is quite modest and this in turn limits the mediating role of obligations. There are many ways to account for this. It might be the case that community institutions such as the church and the school have lost some of their power to influence how much we feel responsible for the welfare of others: "It has become a matter of individual 
parental discretion whether or to what extent a child receives some socialization with respect to responsibility" (Markus, Ryff, Conner, Pudberry, and Barnett 2001:351). Second, the meaning of social responsibility might be moving away from community service. For many Americans today, being socially responsible consists of taking care of themselves, their jobs, and their own families (Markus et al. 2001:361). Young people are being taught to be responsible but not in a way to encourage collective action. Third, a new attitude toward volunteering has emerged in which its dutiful aspects are downplayed and its "fun" aspects emphasized. More and more people are engaging in what volunteer practitioners call "episodic volunteering" that "does not require great social or personal sacrifice" (Eikenberry 2009:54).

On the other hand, it is possible that the effect of obligations is being underestimated in this study. First, although respondents are asked to imagine being placed in situations where certain obligations are present, they are not actually in those situations. To influence behavior, people must come to believe that norms enjoining social responsibilities apply to them personally. Second, "ecological and contextual factors may constrain the definition and enactment of socially responsible behaviors" (Rossi 2001:180). This is brilliantly demonstrated in Eckstein's (2001) study of a Boston neighborhood where norms of reciprocity and social responsibility mobilize volunteer work for a wide variety of social causes and social events. But Eckstein is careful to point out that norms will be efficacious only under certain conditions: communities must be stable, relatively homogeneous, have a shared culture of giving, and so on. Under these conditions norms can be taught and learned and can be enforced by social disapproval of rule breakers. A nationally random sample of the population obscures these ecological distinctions.

\section{Limitations}

In the introduction to this article, we listed a variety of possible mechanisms linking religion and education to volunteering. We do not claim that norms are the only, or even the most important, mediator. Indeed, some of the direct effects shown in our models, such as that between education and 2005 volunteering or 1995 religiosity and 2005 volunteering, could easily conceal additional mechanisms, as we noted earlier. Second, the education variable is a crude measure of educational socialization. It remains to be seen whether obligations would play a more prominent role if data were available on the quality or content of education as well as its duration (Nie and Hillygus 2001). What is the effect of civics education, types of school, service learning, and particular majors or concentrations on altruistic or civic obligations? Third, MIDUS does not provide a measure of the respondent's religiosity prior to 1995 except the importance attached to religion in the respondent's childhood home. Although there is quite a strong correlation between the religiosity of the home and the respondent's religiosity in 1995, some people who were religious in 1995 did not have a religious upbringing and some people who had a religious upbringing were not religious in 1995. A measure of the respondent's own religiosity earlier in life would have been preferable..

In this study, we did not discriminate between different types of volunteering, although it is quite plausible that they would relate to obligations in different 
ways. We did not pursue this line of investigation for the following reasons. First, the list of types of organizations provided in the MIDUS survey is short and somewhat arbitrary. With only three identified types and an amorphous "Other" category, the typology is simply inadequate for the purpose. Second, the distribution in some of the types identified by MIDUS is highly skewed: only 7 percent (1995) and 9 percent (2005) of the respondents had volunteered for a health-related organization, and only 5 percent (1995) and 6 percent (2005) had volunteered for a political organization. Third-and most important given our focus on the influence of religion on volunteering - the typology does not distinguish volunteering in connection with a religious organization, which is by far the most common type of volunteer work in the United States. [We did, however, experiment with a measure of the range of volunteering (i.e., a count of the number of volunteer activities reported by the respondent), but the results were no different.]

\section{CONCLUSION}

This study shows that norms do make a difference to helping behavior, despite the skepticism that has greeted this claim in the past. The effect of obligations on volunteering is as strong as the effect of public religion (refer to Figures 2 and 3), a factor widely considered to be one of the most robust predictors of volunteer behavior. Of course, norms are not the only determinant of volunteerism, which range from personality traits to economic and social interests. But future research should devote more attention to possible variations in who is most likely to be motivated by norms to do volunteer work. Which groups in the population are most likely to conform to the norm? Future research should also investigate how norms and other predictors of volunteer work interact with each other. For example, it is quite possible that a sense of obligation to help others affects how we calculate the value of our free time: those of us who feel strongly that working on behalf of others is important are more likely to "find time" to do volunteer work.

\section{APPENDIX}

Chi-Square Tests of Equality Constraint on Altruistic and Civic Obligations of Their Effects on 2005 Volunteering Using Multiply-Imputed Data

\begin{tabular}{lccccl}
\hline & $\begin{array}{c}\text { Altruistic } \\
\text { Imputed Data } \\
\text { Obligation }(A O)\end{array}$ & $\begin{array}{c}\text { Civic Obligation } \\
(C O)\end{array}$ & $\begin{array}{c}\text { Chi-Square Test } \\
\text { of Equality } \\
(d f=1)\end{array}$ & $p$ & Outcome \\
\hline Data 1 & $.04^{*}$ & $.09^{* * *}$ & 4.087 & $0.043^{*}$ & $\mathrm{AO}<\mathrm{CO}$ \\
Data 2 & $.08^{* * *}$ & $.05^{*}$ & 0.534 & 0.465 & $\mathrm{AO}=\mathrm{CO}$ \\
Data 3 & $.06^{* *}$ & .04 & 0.380 & 0.537 & $\mathrm{AO}=\mathrm{CO}$ \\
Data 4 & .03 & $.10^{* * *}$ & 6.688 & $0.009^{* *}$ & $\mathrm{AO}<\mathrm{CO}$ \\
Data 5 & .01 & $.13^{* * *}$ & 16.796 & $0.000^{* * *}$ & $\mathrm{AO}<\mathrm{CO}$ \\
\hline
\end{tabular}

Note: $\beta$ (standardized) coefficients are reported. The SEM software (Mplus) does not allow a test of equality constraint on multiply-imputed data sets concurrently. Thus, the test was applied to each of the five imputed data sets. For the tests, the MLMV (maximum likelihood parameter estimates with standard errors and a mean- and variance-adjusted chi-square test statistic) estimator was employed. ${ }^{*} p<.05 ;{ }^{* *} p<.01 ;{ }^{* * *} p<.001$ (two-tailed). 


\section{REFERENCES}

Abraham, Katharine, Sara Helms, and Stanley Presser. 2009. “How Social Processes Distort Measurement: The Impact of Survey Nonresponse on Estimates of Volunteer Work in the United States." American Journal of Sociology 114:1129-65.

Ammerman, Nancy. 1997. Congregation and Community. New Brunswick, NJ: Rutgers University Press.

—. 2002. "Connecting Mainline Churches with Public Life." Pp. 129-58 in The Quiet Hand of God: Faith-Based Activism and the Public Role of Mainline Protestantism, edited by R. Wuthnow. Berkeley: University of California Press.

Arbuckle, James L. 1996. "Full Information Estimation in the Presence of Incomplete Data." Pp. 243-77 in Advanced Structural Equation Modeling: Issues and Techniques, edited by G. A. Marcoulides and R. E. Schumacker. Mahwah, NJ: Lawrence Erlbaum Associates, Inc.

Beyerlein, Kraig and John Hipp. 2006. "From Pews to Participation: The Effects of Congregation Activity and Context on Bridging Civic Engagement." Social Problems 53(1):97-117.

Brown, Eleanor and James Ferris. 2007. "Social Capital and Philanthropy: An Analysis of the Impact of Social Capital on Individual Giving and Volunteering." Nonprofit and Voluntary Sector Quarterly 36:85-99.

Campbell, David. 2006. Why We Vote: How Schools and Communities Shape Our Civic Life. Princeton, NJ: Princeton University Press.

Chaves, Mark. 2004. Congregations in America. Cambridge, MA: Harvard University Press.

Dekker, Paul. 2004. "Social Capital of Individuals: Relational Asset or Personal Quality?" Pp. 88-110 in Investigating Social Capital, edited by S. Prakash and P. Selle. Thousand Oaks, CA: Sage.

DeVoe, Sanford and Jeffrey Pepper. 2007. "Hourly Payment and Volunteering: The Effects of Organizational Practices on Decisions about Time Use." Academy of Management Journal 50(4):783-98.

Driskell, Robyn, Larry Lyon, and Elizabeth Embry. 2008. "Civic Engagement and Religious Activities: Examining the Influence of Religious Tradition and Participation." Sociological Spectrum 28(5):578-601.

Durkheim, Emile. 1961. Moral Education. New York: Free Press.

Eckstein, Susan. 2001. "Community as Gift-Giving: Collectivist Roots of Volunteerism." American Sociological Review 66:829-51.

Eikenberry, Angela. 2009. Giving Circles: Philanthropy, Voluntary Association and Democracy. Indianapolis: Indiana University Press.

Einolf, Christopher. 2011. "Daily Spiritual Experiences and Prosocial Behavior." Social Indicators Research. Available at http://www.springerlink.com.proxy.lib.duke.edu/ content/06251844k3410144/fulltext.pdf

Ferree, G. Donald, John Barry, and Bruno Manno. 1998. The National Survey of Philanthropy and Civic Renewal. Washington, DC: National Commission on Philanthropy and Civic Renewal.

Galston, William. 2007. "Civic Knowledge, Civic Education and Civic Engagement." Pp. 95-112 in Fountain of Youth: Strategies and Tactics for Mobilizing America's Young Voters, edited by D. Shea and J. C. Green. Lanham, MD: Rowman and Littlefield.

Graham, John W. 2009. "Missing Data Analysis: Making It Work in the Real World." Annual Review of Psychology 60:549-76. 
Hechter, Michael and Karl-Dieter Opp. 2001. “Introduction” Pp. xi-xx in Social Norms, edited by M. Hechter and K.-D. Opp. New York: Russell Sage Foundation.

Herman, Melissa and Mary Campbell. 2011. "II Wouldn't but You Can': Attitudes toward Interracial Relationships." Social Science Research 41: 343-58.

Hillygus, D. Sunshine. 2005. "THE MISSING LINK: Exploring the Relationship between Higher Education and Political Engagement." Political Behavior 27:25-47.

Hodgkinson, Virginia and Murray Weitzman. 1996. Giving and Volunteering in the United States. Washington, DC: The Independent Sector.

Markus, Helen, Carol Ryff, Alana Conner, Eden Pudberry, and Katherine Barnett. 2001. "Themes and Variations in American Understandings of Responsibility." Pp. 349-402 in Caring and Doing for Others, edited by A. Rossi. Chicago: University of Chicago Press.

Matsuba, M. Kyle, Daniel Hart, and Robert Atkins. 2007. "Psychological and Social-Structural Influences on Commitment to Volunteering." Journal of Research in Personality 41:889-907.

Musick, Marc and John Wilson. 2008. Volunteers: A Social Profile. Indianapolis: Indiana University Press.

Muthén, Linda K. and Bengt O. Muthén. 2010. Mplus User's Guide. Los Angeles, CA: Muthén \& Muthén.

Nie, Norman and D. Sunshine Hillygus. 2001. "Education and Democratic Citizenship." Pp. 30-57 in Making Good Citizens, edited by D. Ravitch and J. Viterriti. New Haven, CT: Yale University Press.

Oesterle, Sabrina, Monica Kirkpatrick Johnson, and Jeylan Mortimer. 2004. "Volunteerism during the Transition to Adulthood." Social Forces 82:1123-49.

Pancer, S. Mark and Michael Pratt. 1999. "Social and Family Determinants of Community Service Involvement in Canadian Youth." Pp. 32-55 in Roots of Civic Identity: International Perspectives on Community Service and Activism in Youth, edited by M. Yates and J. Youniss. Cambridge, UK: Cambridge University Press.

Peugh, James L. and Craig K. Enders. 2004. "Missing Data in Educational Research: A Review of Reporting Practices and Suggestions for Improvement." Review of Educational Research 74:525-56.

Putnam, Robert. 2000. Bowling Alone: The Collapse and Revival of American Community. New York: Simon and Schuster.

Radler, Barry and Carol Ryff. 2010. "Who Participates? Accounting for Longitudinal Retention in MIDUS National Study of Health and Well-Being." Journal of Aging and Health 22(3):307-31.

Reed, Paul and L. Kevin Selbee. 2003. "Do People Who Volunteer Have a Distinctive Ethos? A Canadian Study." Pp. 91-110 in The Values of Volunteering: A Cross-Cultural Perspective, edited by P. Dekker and L. Halman. New York: Kluwer Academic.

Regnerus, Mark. 2003. "Religion and Positive Adolescent Outcomes: A Review of Research and Theory." Review of Religious Research 44(4):394-413.

Riedel, Eric. 2002. "The Impact of High School Community Service Programs on Students' Feelings of Civic Obligation." American Politics Research 30:499-527.

Rossi, Alice. 2001. "Domains and Dimensions of Social Responsibility." Pp. 97-134 in Caring and Doing for Others, edited by A. Rossi. Chicago: University of Chicago Press.

- 2004. "Social Responsibility to Family and Community." Pp. 550-85 in How Healthy Are We? A National Study of Well-Being in Midlife, edited by O. Brim, C. Ryff, and R. Kessler. Chicago: University of Chicago Press. 
Royston, Patrick. 2005. “Multiple Imputation of Missing Values: Update.” Stata Journal 5:1-14. Rubin, Donald B. 1976. "Inference and Missing Data." Biometrika 63:581-92.

Saroglou, Vassilis, Isabelle Pichon, Laurence Trompette, Marijke Verschueren, and Rebecca Dernelle. 2005. "Prosocial Behavior and Religion: New Evidence Based on Projective Measures and Peer Ratings." Journal for the Scientific Study of Religion 44(3):323-48.

Satorra, Albert. and Peter. M. Bentler. 2001. "A Scaled Difference in Chi-Square Test Statistic for Moment Structure Analysis." Psychometrica 66:507-14.

Schafer, Joseph L. 2003. “Multiple Imputation in Multivariate Problems When the Imputation and Analysis Models Differ." Statistica Neerlandica 57:19-35.

Schwartz, Shalom. 1973. "Normative Explanations of Helping Behavior." Journal of Experimental Social Psychology 9:349-64.

Sewell, William, Jr. 1992. "A Theory of Structure: Duality, Agency and Transformation." American Journal of Sociology 98(1):1-29.

Steensland, Brian, Jerry Park, Mark Regnerus, Lynn Robinson, W. Bradford Wilcox, and Robert Woodbery. 2000. "The Measure of American Religion: Toward Improving the State of the Art." Social Forces 79(1):291-318.

Sundeen, Richard. 1992. "Differences in Personal Goals and Attitudes among Volunteers." Nonprofit and Voluntary Sector Quarterly 21:271-91.

Taniguchi, Hiromi and Leonard Thomas. 2010. "The Influence of Religious Attitudes on Volunteering." Voluntas 22(2):335-55.

U.S. Bureau of Labor Statistics. 2008. Volunteering in the United States. Washington, DC: Government Printing Office.

Uslaner, Eric. 2002. The Moral Foundation of Trust. Cambridge, UK: Cambridge University Press.

Van Buuren, S., H. C. Boshuizen, and D. L. Knook. 1999. “Multiple Imputation of Missing Blood Pressure Covariates in Survival Analysis." Statistics in Medicine 18:681-94.

Verba, Sidney, Kay Lehman Schlozman, and Henry Brady. 1995. Voice and Equality: Civic Voluntarism in American Politics. Cambridge, MA: Harvard University Press.

Wilson, John. 1978. Religion in American Society: The Effective Presence. Englewood Cliffs, NJ: Prentice Hall.

—. 2005. "Some Things Social Surveys Do Not Tell Us about Volunteering." Pp. 11-26 in Processes of Community Change and Social Action, edited by A. Omoto. Mawah, NJ: Lawrence Erlbaum and Associates. and Thomas Janoski. 1995. "The Contribution of Religion to Volunteer Work." Sociology of Religion 56:137-52. and Marc Musick. 1997. "Who Cares? Toward an Integrated Theory of Volunteer Work." American Sociological Review 62:694-713.

Wuthnow, Robert. 1995. Learning to Care: Elementary Kindness in an Age of Indifference. New York: Oxford University Press. 
Reproduced with permission of the copyright owner. Further reproduction prohibited without permission. 